\title{
E-cadherin gene polymorphisms in asthma patients using inhaled corticosteroids
}

\author{
D. Ierodiakonou*, D.S. Postma*, G.H. Koppelman`, H.M. Boezen*, J. Gerritsen \\ N. ten Hacken ${ }^{\#}$, W. Timens ${ }^{+}$and J.M. Vonk*
}

ABSTRACT: E-cadherins form intercellular junctions that maintain epithelial integrity. Epithelial integrity is impaired in asthma and can be restored by inhaled corticosteroids (ICSs). Our aim was to investigate the association of $\mathrm{CDH} 1$ gene polymorphisms (single-nucleotide polymorphisms (SNPs)) with airway remodelling, inflammation and forced expiratory volume in $1 \mathrm{~s}$ (FEV1) decline in asthma patients and assess whether ICSs modulate these effects.

Bronchial biopsies of 138 asthmatics were available (population 1). Associations of 17 haplotype-tagging SNPs with epithelial E-cadherin expression, biopsy parameters and FEV $1 /$ vital capacity (VC) ratio were tested. FEV1 and VC data were collected in 281 asthmatics with 30-yr follow-up (population 2). Linear mixed-effect models were used to assess associations of SNPs with FEV 1 decline.

Seven out of the 17 SNPs were associated with airway remodelling, three with CD8+ T-cell counts, two with eosinophil counts and seven with FEV1 decline. All associations occurred only in patients using ICS. In general, alleles associated with less remodelling correlated with less FEV 1 decline and higher FEV1/VC. Decreased epithelial E-cadherin expression was associated with five SNPs in non-ICS users.

In conclusion, our data show that $\mathrm{CDH} 1$ polymorphisms are associated with epithelial Ecadherin expression and suggest that epithelial adhesion is an important contributor to airway remodelling and lung function in asthma. These effects are modified by the use of inhaled corticosteroids.

KEYWORDS: Airway remodelling, asthma, epithelial cadherin, epithelium, glucocorticosteroids, polymorphisms

A sthma is a chronic inflammatory disease of the airways characterised by bronchial hyperresponsiveness (BHR), and pathological changes in the epithelium and submucosal area of the bronchi. Histological studies indicate that the epithelium is interrupted and fragile in bronchial biopsies from asthmatics [1, 2]. Both genetic and environmental factors as well as their interactions are involved in asthma development and its course during lifetime. Recent advances in the understanding of the pathophysiology of asthma have pointed towards a prominent role of the airway epithelium in asthma development and severity $[3,4]$.

Airway epithelium is the natural barrier between the environment and underlying tissue. Its integrity is important for protecting the airways against noxious inhalants, such as environmental tobacco smoke, particles and biological agents.
Regulation of cell-cell junction stability and dynamics is crucial to maintaining tissue integrity and allowing tissue remodelling throughout development $[5,6]$. E-cadherin, the major cadherin expressed in epithelial cells, is an adhesion molecule that is able to establish and stabilise cellular junctions between adjacent cells in the presence of $\mathrm{Ca}^{2+}$ [7] and is coded by the $\mathrm{CDH1}$ gene on chromosome 16q22.1. HiROSAKO et al. [8] suggested that human bronchial intraepithelial lymphocytes have roles distinct from subsets of other lymphocytes, and that CD8+ cells and CD103+ (ligand of Ecadherin) cells have potentially important functions in the bronchial epithelium.

Longitudinal studies have demonstrated that some asthma patients develop irreversible airway obstruction and progressive loss of lung function [9]. Inhaled corticosteroids (ICSs) have been widely used for suppressing inflammation and
AFFILIATIONS

Depts of *Epidemiology,

\#Pulmonology,

"Paediatric Pulmonology and Paediatric Allergology, Beatrix Children's Hospital, and

+Pathology and Medical Biology, University Medical Center Groningen (UMCG), University of Groningen, Groningen, The Netherlands.

CORRESPONDENCE

J.M. Vonk

Dept of Epidemiology, University Medical Center Groningen University of Groningen Hanzeplein 1 9700 RB Groningen

P.0. Box 30.001

The Netherlands

E-mail: j.m.vonk@umcg.nl

Received:

Dec 162010

Accepted after revision:

April 062011

First published online:

May 032011 
asthma symptoms. Early use of ICSs has been found to be associated with less accelerated forced expiratory volume in $1 \mathrm{~s}$ (FEV1) decline [10], and with improvement of BHR and airway remodelling [11]. Furthermore, corticosteroids are thought to modulate epithelial repair [12] and there is evidence that they upregulate epithelial E-cadherin expression [13].

We hypothesised that loss of epithelial integrity resulting from loss of epithelial E-cadherin expression or disruption of Ecadherin-mediated cell-cell contacts predisposes airways to abnormal responses to inhaled substances. Subsequent remodelling processes and airway inflammation may lead to airway narrowing and accelerated lung function decline.

Therefore, we investigated the associations between $\mathrm{CDH} 1$ polymorphisms and airway remodelling (basement membrane (BM) thickness and subepithelial vasculature), inflammation and annual FEV1 decline in asthma patients and assessed whether ICS use modulates these associations.

\section{MATERIALS AND METHODS Populations \\ Population 1}

Population 1 consisted of 138 asthmatics who had participated in cohort studies conducted by our research group in previous years. They were re-examined for lung function and BHR, and underwent bronchoscopy with biopsy collection [14, 15]. The main exclusion criteria were: FEV1 $<1.2 \mathrm{~L}$; bronchiectasis; upper respiratory tract infection (e.g. colds); and/or use of antibiotics or oral corticosteroids within the 2 months before inclusion. DNA samples and biopsy data were available in 137 subjects.

\section{Population 2}

Population 2 consisted of 281 asthma patients who had been referred to the asthma clinic at Beatrixoord Hospital in Haren, the Netherlands, over the period 1966-1975. Patients who, at their first visit, were $<45$ yrs of age, had $\geqslant 20 \%$ fall in FEV1 during a histamine challenge test (provocative concentration causing a $20 \%$ fall in FEV1 $\leqslant 32 \mathrm{mg} \cdot \mathrm{mL}^{-1}$ ) and were symptomatic according to current American Thoracic Society criteria [16] were re-examined during the period 1991-1999 [9]. At both visits, patients filled in a questionnaire on respiratory symptoms and underwent lung function, histamine challenge and skinprick tests. The clinical assessment was performed as previously described [10]. Before testing, participants had to be in a stable condition without any exacerbation in the previous 6 weeks. After their first visit, subjects had annual routine check-ups for their asthma. Their medical records provided information on lung function and corticosteroid use during these check-ups. DNA samples have been collected from 253 subjects. 32 subjects in population 1 were derived from population 2. All participants originated from the northern region of the Netherlands. The study was approved by the medical ethics committee of the University Medical Center Groningen (Groningen, the Netherlands), and all participants gave signed, informed consent.

\section{Biopsy collection and processing}

Bronchoscopy, collection and processing of the bronchial biopsies were performed as previously described [14]. Immunohistochemistry was performed on $3-\mu \mathrm{m}$, formalin-fixed, paraffin-embedded tissue specimens that were deparaffinised with xylene, dehydrated in ethanol and after antigen retrieval, incubated with the primary antibodies: anti-E-cadherin antibody (\#610181; BD Bioscience, Breda, the Netherlands) for epithelial Ecadherin expression; anti-eosinophilic peroxidase antibody for eosinophil detection (laboratories of N.A. Lee and J.J. Lee, Mayo Clinic, Scottsdale, AZ, USA); anti-CD8 (DAKO, Heverlee, the Netherlands) antibody for T-cells; and anti-CD31 monoclonal antibody for vessel endothelial cells. BM thickness was calculated by dividing the BM surface area by BM length $(\mu \mathrm{m})$. The number of positively stained inflammatory cells was counted in a total area of $0.1 \mathrm{~mm}^{2}$ in the submucosa, $100 \mu \mathrm{m}$ beneath the BM. The number of CD31+ vessels in the submucosal area was counted in the whole section (excluding epithelium, muscle and mucous gland areas); therefore, we measured the number of vessels per area $\left(0.1 \mathrm{~mm}^{2}\right)$. Finally, Ecadherin expression was determined as the percentage of BM covered with E-cadherin-positive intact epithelium (fig. 1). Further details on the immunochemistry and quantification procedures used are presented in the online supplementary material.

\section{Genotyping of single-nucleotide polymorphisms}

We genotyped 17 haplotype-tagging single-nucleotide polymorphisms (SNPs) in CDH1 according to HapMap CEU (Utah residents with Northern and Western European ancestry) genotype data $\left(\mathrm{r}^{2}<0.8\right.$; minor allele frequency $\left.>10 \%\right)$. 12 of the SNPs were genotyped by KBioscience Ltd (Hoddesdon, UK) using their competitive allele-specific PCR system (KASPar), and five SNPs were derived from a genome-wide association study on asthma using the $370-\mathrm{kb}$ Illumina chip (Illumina, Eindhoven, the Netherlands) (see figure 2 for the genotyped SNPs).

\section{Statistics}

Normalisation of the distribution of the variables was performed by natural logarithm transformation where necessary. Multiple linear regression analysis adjusted for sex, age and smoking was used to assess the effect of the SNPs on airway remodelling parameters (BM thickness and submucosal vessel numbers) and inflammatory cells (eosinophils and CD8+T-cells) in population 1. Additionally, we used FEV1/ vital capacity (VC) ratio post-bronchodilation (BD) adjusted for sex, age, height and smoking as a marker of remodelling in both populations [17]. Since E-cadherin expression is known to be upregulated by ICSs [13, 18, 19], we tested for interaction between ICS and genotypes by introducing interaction terms into the models. General (heterozygotes versus wild types and homozygous mutants versus wild types) genetic models were used. When the number of subjects with the homozygote mutant genotype was less than five, only dominant (heterozygotes and homozygous mutants pooled versus wild types) models were used. Association between epithelial E-cadherin expression (percentage of BM covered with intact epithelium positive for E-cadherin) and genotypes was assessed with nonparametric tests using dominant genetic models. The association between denuded epithelium (percentage BM covered with denuded epithelium) and epithelial E-cadherin expression was tested with multiple linear regression adjusted for sex and age. In population 2, FEV1 decline was analysed with linear mixed-effect (LME) models as described previously [10]. Only FEV1 measurements after the age of $30 \mathrm{yrs}$ 

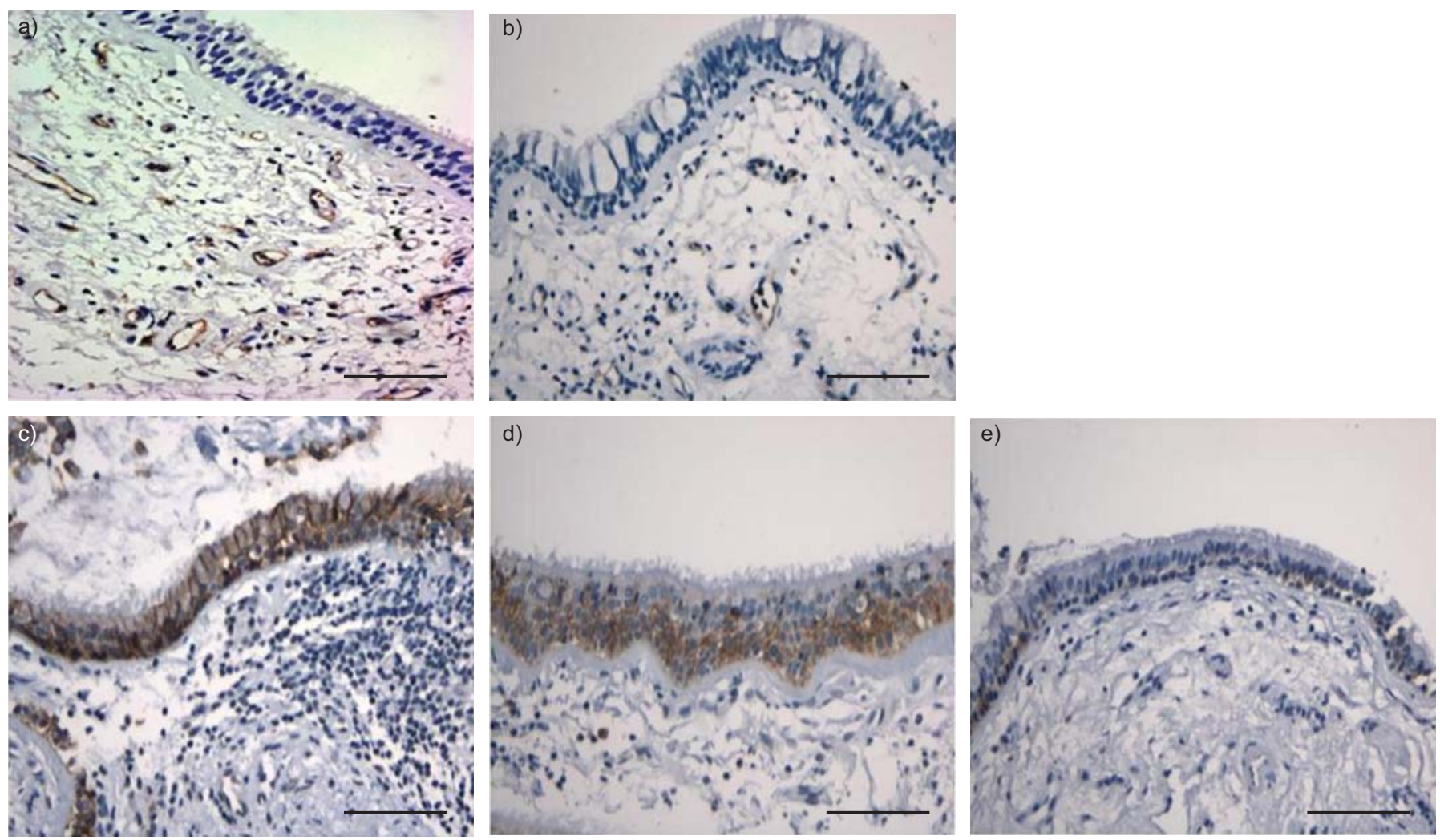

FIGURE 1. Immunostaining of airway wall biopsies of asthma patients. Representative images of a) strong and b) weak CD31 staining of vessels, and c) strong d) moderate and e) weak epithelial E-cadherin staining. Magnification: objective $20 \times$. Scale bars $=150 \mu \mathrm{m}$.

were included, since this is the age where the lung function is in a plateau phase or decline begins in normal subjects [20]. LME models were adjusted for sex, age, first FEV1 after age $30 \mathrm{yrs}$, height, pack-years of smoking and use of oral corticosteroids. Inclusion criteria required subjects having FEV1 measurements before and after the introduction of ICS, with a minimum of three FEV1 measurements over a period of $\geqslant 2$ yrs. Subjects who never used ICSs were excluded. FEV1 levels and annual FEV1 declines were estimated for the two periods (without and with ICS use) by introducing the following variables: time; genotype; ICS use; and their interactions. LME models were conducted in S-plus 7.0 (Insightful Corp., Seattle, WA, USA). All other analyses were conducted with SPSS (version 16; SPSS Inc., Chicago, IL, USA). Two-tailed p-values of $<0.05$ were considered statistically significant.

\section{RESULTS}

\section{Clinical characteristics and genotype distribution}

Clinical characteristics of both populations are presented in table 1. All subjects were atopic and hyperresponsive at first clinical assessment. Population 1 had a higher mean lung function and $57(41.3 \%)$ subjects used ICS, while $146(52 \%)$ subjects were on ICS treatment in population 2. For the analysis on FEV1 decline 125 subjects met the inclusion criteria. Table 2 presents details on corticosteroid use in populations 1 and 2. Genotype distributions in the two asthmatic populations are presented in table E1 in the online supplementary material. All SNPs were in Hardy-Weinberg equilibrium ( $p>0.05)$. The linkage disequilibrium (LD) plot of the SNPs in population 2 is shown in figure 2.

\section{Epithelial E-cadherin expression}

Five CDH1 SNPs were significantly associated with epithelial Ecadherin expression (rs8056633, rs16958383, rs2276330, rs3785078 and rs7203904). The minor alleles of these SNPs were significantly associated with lower expression of E-cadherin in individuals without ICS and generally with similar expression as the wild types in those with ICS use (table 3 and fig. 3; table E2 in the online supplementary material). There were no significant differences in epithelial E-cadherin expression between neverand ever- (ex- and current pooled) smokers or among the three smoking categories (data not shown). The association between denuded epithelium with epithelial E-cadherin expression was very close to significance $(b=-0.003 ; p=0.05$; natural logarithm scale).

\section{Airway remodelling: BM thickness and subepithelial vasculature}

In population 1, seven out of 17 SNPs were associated with BM thickness and subepithelial vasculature in the presence of ICS (rs7188750, rs8056633, rs16958383, rs2276630, rs3785078, rs7203904 and rs17690554). The minor alleles of these polymorphisms were all associated with thinner BM and/or a lower number of vessels in the submucosal area (table 3 and fig. 3). Without ICS use, these effects of the minor alleles were less prominent or even reversed, but not significantly so. Interactions between these SNPs and ICSs with respect to airway remodelling 


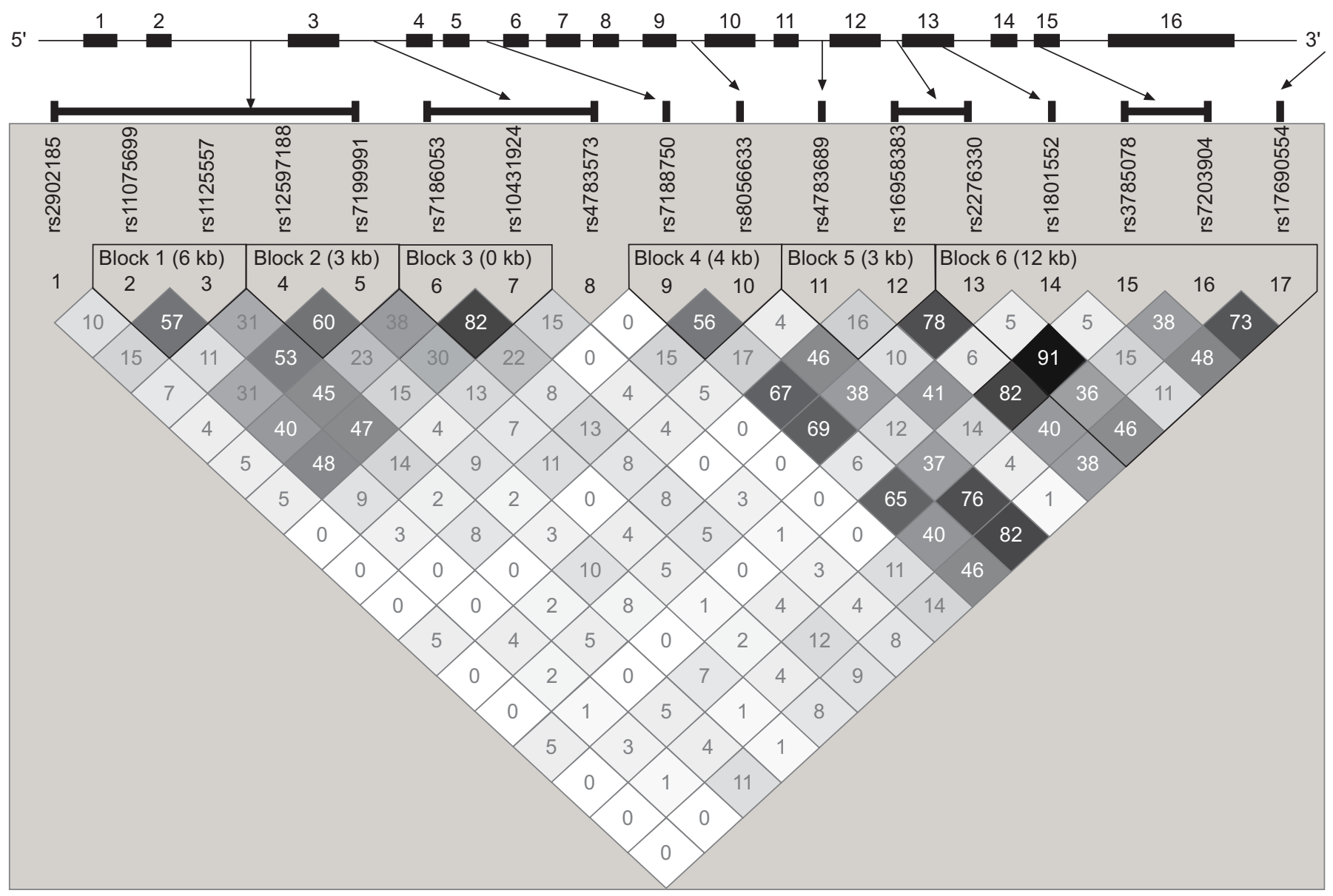

FIGURE 2. Linkage disequilibrium plot and correlation coefficients $\left(100 r^{2}\right)$ of 17 genotyped CDH1 gene single-nucleotide polymorphisms (SNPS) in population 2 $(n=281)$. The location of SNPs is given for the HapMap (www.hapmap.org).

were significant for rs2276330 and rs3785078 (tables E3.1 and E3.2 in the online supplementary material).

\section{Airway inflammation: submucosal CD8+ T-cell and eosinophil counts}

With ICS use, rs11075699, rs2276630 and rs1125557 were significantly associated with CD8+ T-cell counts in the submucosal area. CD8+ T-cell counts were higher in subjects heterozygous for rs11075699 and in carriers of the minor Callele of rs2276330, while subjects with a homozygous mutant genotype for rs1125557 had lower CD8+T-cell counts compared with wild-types. Minor alleles of rs2902185 and rs10431924 were associated with higher eosinophil counts. These associations were absent in asthmatics without ICS. Interactions between SNPs and ICSs on inflammatory cell counts (CD8+ T-cells and eosinophils) were statistically significant for three out of five SNPs (rs1125557, rs10431924 and rs2276330) and for rs7188750, respectively (fig. 3; tables $\mathrm{E} 4.1$ and $\mathrm{E} 4.2$ in the online supplementary material).

\section{FEV1 decline and FEV1/VC}

Seven out of 17 SNPs were significantly associated with FEV1 decline in the presence of ICSs. The minor alleles for rs8056633, rs16958383, rs7203904 and rs17690554 were associated with less FEV1 decline. For example, during ICS use, FEV1 decline was $20.4 \mathrm{~mL} \cdot \mathrm{yr}^{-1}$ for subjects with the wild-type genotype of rs16958383, while it was $36.6 \mathrm{~mL} \cdot \mathrm{yr}^{-1}$ less in homozygous carriers of the minor allele $(p=0.004$; fig. 3$)$. The minor alleles for rs1125557, rs7199991 and rs7186053 were associated with accelerated FEV1 decline. A significant interaction of ICS with CDH1 SNPs on FEV1 decline was present only for rs7199991 and rs3785078. There were no associations with lung function decline in the absence of ICS use (table 3; table E5 in the online supplementary material).

In population 2, SNPs that were associated with less FEV1 decline were also associated with higher post-BD FEV1/VC with ICS use. Additionally, rs4783573, rs7188750 and rs3785078 were associated with higher post-BD FEV1/VC (table 3 and fig. 3). Interactions of these SNPs with ICSs on post-BD FEV1/ VC were significant. In population 1 , these SNPs had the same direction of association with post-BD FEV1/VC, but only the interaction with rs7203904 was significant (tables E6.1 and E6.2 in the online supplementary material).

\section{DISCUSSION}

Our results indicate that E-cadherin (CDH1) gene polymorphisms are associated with airway remodelling, inflammation and lung function decline in individuals with asthma. In 


\begin{tabular}{|c|c|c|}
\hline & Population 1 & Population 2 \\
\hline Asthmatics $\mathrm{n}$ & 138 & 281 \\
\hline Year of assessment & 2002-2006 & 1991-1999 \\
\hline Males \% & 50.7 & 60.5 \\
\hline Age yrs & $47.2 \pm 12.7$ & $51.3 \pm 9.1$ \\
\hline ICS use & $57(41.3)$ & $146(52.0)$ \\
\hline LABA use & $37(26.8)$ & NA \\
\hline Non/ex-/current smokers \% & $44.9 / 34.1 / 21.0$ & $40.6 / 32.0 / 27.4$ \\
\hline \multicolumn{3}{|l|}{ FEV $_{1} \%$ pred } \\
\hline Pre-BD & $91.7 \pm 18.0$ & $70.1 \pm 23.6$ \\
\hline Post-BD & $99.9 \pm 17.0$ & $82.5 \pm 22.4$ \\
\hline \multicolumn{3}{|l|}{$\mathrm{FEV}_{1} / \mathrm{VC}$} \\
\hline Pre-BD & $71.2(8.8)$ & $60.2(14.2)$ \\
\hline Post-BD & $75.6(6.5)$ & $64.8(13.5)$ \\
\hline CD31+ vessels $^{\#} \mathbf{n}$ & $18.0 \pm 8.2$ & NA \\
\hline BM thickness $\mu \mathrm{m}$ & $6.0 \pm 1.6$ & NA \\
\hline CD8+ cells ${ }^{\#} \mathbf{n}$ & $23.0(1-204)$ & NA \\
\hline EPX+ cells ${ }^{\#} n$ & $2.0(0-40)$ & NA \\
\hline Epithelial E-cadherin expression & $88.4(0-100)$ & NA \\
\hline
\end{tabular}

Data are presented in mean $\pm \mathrm{SD}, \mathrm{n}(\%)$ or median (range), unless otherwise stated. ICS: inhaled corticosteroid; LABA: Iong-acting $\beta$-agonist; FEV1: forced expiratory volume in $1 \mathrm{~s}$; \% pred: \% predicted; BD: bronchodilation; VC: vital capacity; BM: basement membrane; EPX: eosinophilic peroxidase; NA: not applicable. * : per $0.1 \mathrm{~mm}^{2}$ submucosal area; ${ }^{\circ}$ : \% BM covered with E-cadherinpositive intact epithelium.

TABLE 2

Characteristics of corticosteroid use in populations 1 and 2

\begin{tabular}{|c|c|c|}
\hline & Population 1 & Population 2 \\
\hline Total subjects $n$ & 138 & 281 \\
\hline Subjects using ICSs at final survey & $57(41.3)$ & $146(52.0)$ \\
\hline ICS dose ${ }^{\#} \mu \mathrm{g} \cdot$ day $^{-1}$ & $800(100-2000)$ & $800(50-6000)$ \\
\hline Subjects using OCSs at final survey & 0 & $14(5.0)$ \\
\hline $\begin{array}{l}\text { Subjects using LABAs among ICS } \\
\text { users }\end{array}$ & $31(54.4)$ & NA \\
\hline \multicolumn{3}{|l|}{$\begin{array}{l}\text { Subjects included in analysis of FEV } 1 \\
\text { decline }\end{array}$} \\
\hline Subjects who ever used ICSs & & $125(100.0)$ \\
\hline Subjects who ever used OCSs & & $69(55.2)$ \\
\hline Age at start of ICS use yrs & & $42(21-70)$ \\
\hline Duration of ICS use yrs & & $13.5(2.2-25.7)$ \\
\hline ICS dose ${ }^{\#} \mu \mathrm{g} \cdot$ day $^{-1}$ & & $694(179-2400)$ \\
\hline Duration of OCS use yrs & & $9.8(0.1-34.8)$ \\
\hline OCS dose $\mu \mathrm{g} \cdot$ day $^{-1}$ & & $7.6(2.1-15.0)$ \\
\hline
\end{tabular}

Data are presented as $\mathrm{n}(\%)$ or median (range), unless otherwise stated. ICS: inhaled corticosteroid; OCS: oral corticosteroid; LABA: long-acting $\beta$-agonist; FEV1: forced expiratory volume in $1 \mathrm{~s}$; NA: not applicable. ${ }^{*}$ : all doses were recalculated as beclomethasone equivalents $\left(100 \mu \mathrm{g} \cdot\right.$ day $^{-1}$ beclomethasone is $^{-1}$ equivalent to $100 \mu \mathrm{g} \cdot$ day $^{-1}$ budesonide (not by Turbuhaler ${ }^{\text {* }}$; AstraZeneca, Zoetermeer, the Netherlands), $50 \mu \mathrm{g} \cdot \mathrm{day}^{-1}$ budesonide by Turbuhaler ${ }^{-}$or $50 \mu \mathrm{g} \cdot$ day $^{-1}$ fluticasone); ${ }^{\bullet}$ : only ever-ICS users $(\mathrm{n}=125)$. summary, with ICS use, seven out of the 17 SNPs were associated with airway remodelling, three with CD8+ T-cells counts and two with eosinophil counts in the submucosa, and seven with FEV1 decline. Consistently, alleles associated with less airway remodelling correlated with less FEV1 decline and higher post-BD FEV1/VC. While all associations occurred during ICS use, associations with epithelial E-cadherin expression were significant for five SNPs in the absence of ICSs. These results may indicate that ICSs may influence the way these polymorphisms express their effect and are consistent with in vitro results showing that administration of glucocorticosteroids can upregulate cadherin expression, improve cell-cell contact and strengthen the epithelial barrier $[19,21,22]$

Altered expression of epithelial junction proteins on bronchial epithelium may contribute to a defective epithelial barrier $[1,23]$ with subsequent functional and clinical manifestations. In our longitudinal study (population 2), the minor alleles of three SNPs (rs1125557, rs7199991 and rs7186053) were associated with accelerated FEV1 decline during ICS use. rs7199991 is in complete LD $\left(\mathrm{r}^{2}=1\right.$ according to www.hapmap.org, version 4.0) with a promoter-region SNP (rs16260), suggesting that this may have functional significance. To date, E-cadherin gene polymorphisms have not been studied in asthma, but recent findings have shown associations of CDH1 SNPs with Crohn's disease [24], another impaired epithelial barrier disorder, which may share pathways with asthma [25, 26]. Moreover, in genome-wide association studies, CDH1 has recently been associated with susceptibility to ulcerative colitis [27] and colorectal cancer [28]. The new associations suggest that changes in the integrity of the intestinal epithelial barrier may contribute to the pathogenesis of these diseases; hence, CDH1 polymorphisms are important for understanding the pathogenesis of impaired epithelial barrier diseases.

Additionally, our study showed that the minor alleles of four other SNPs (rs8056633, rs16958383, rs7203904 and rs17690554) were associated with less FEV1 decline. The latter four alleles were also associated with less airway remodelling in biopsies of asthmatics using ICSs in population 1. The fact that we observed a significant decrease in BM thickness in the presence of ICSs is consistent with the findings of BROEKEMA et al. [15], who previously showed that symptomatic asthmatics using ICS in our population 1 had significantly thinner BMs than asymptomatic asthmatics who did not use ICSs (5.7 and $6.5 \mu \mathrm{m}$, respectively; $\mathrm{p}<0.05)$. However, our results highlight that this decrease in BM thickness is probably not present in all asthmatics using ICSs, but only in those with a specific CDH1 genotype.

RASMUSSEN et al. [17] used post-BD FEV1/VC as an indirect measure of airway remodelling, and our results point in the same direction, i.e. alleles associated with less airway remodelling (rs7188750, rs8056633, rs16958383, rs3785078, rs7203904 and rs17690554) were also associated with higher post-BD FEV1/VC and less FEV1 decline in population 2. In population 1, only rs7203904 showed a significant association with FEV1/ $\mathrm{VC}$, which is probably due to lower power: lower number of ICS users (57 (41\%) versus $146(52 \%)$ subjects) and less post-BD FEV1/VC variance (SD 6.5 versus 13.5) compared with population 2. In contrast, KosciucH et al. [29] concluded that there is 


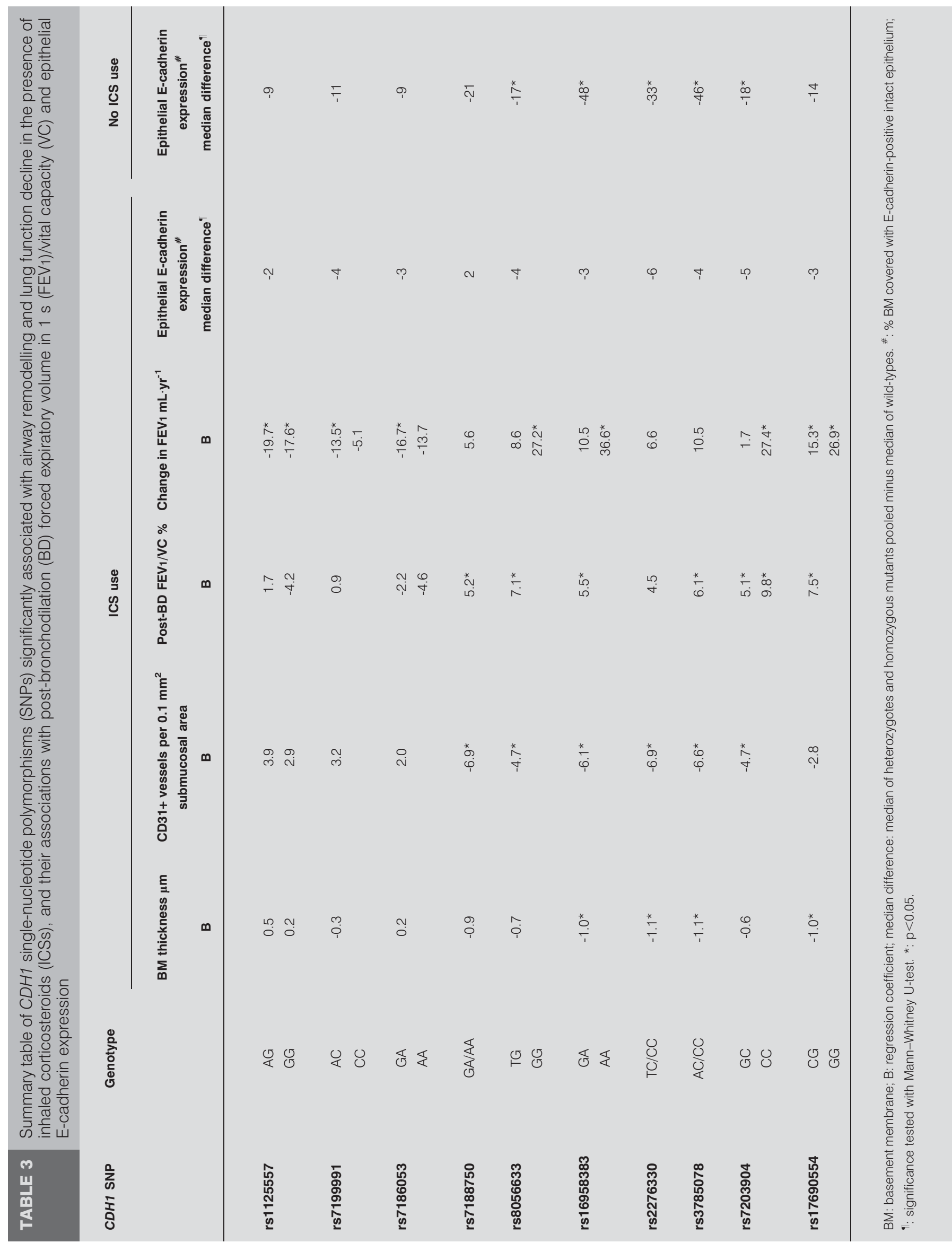



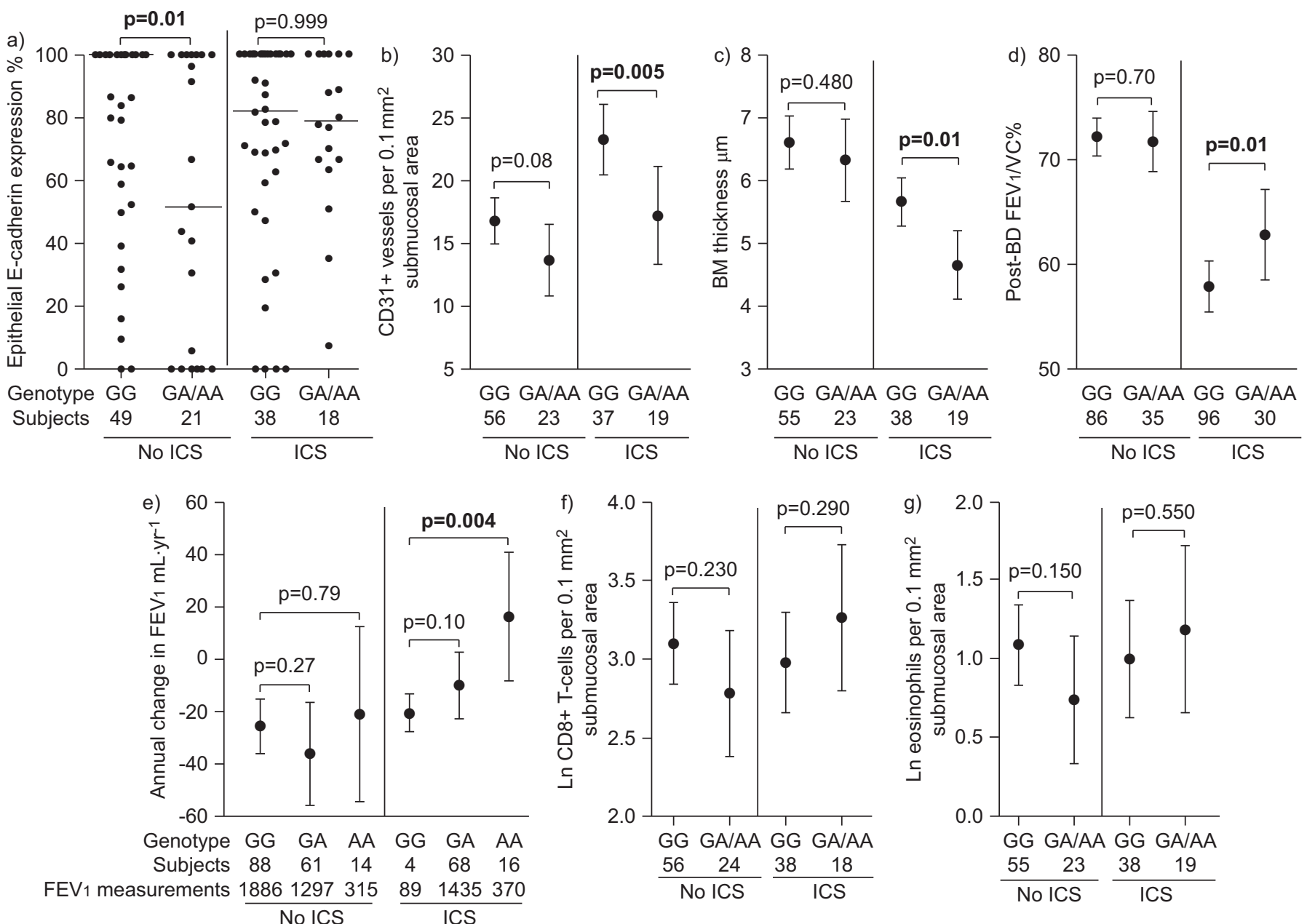

FIGURE 3. CDH1 rs 16958383 associations with epithelial E-cadherin expression, airway remodelling, inflammation and lung function decline in adult asthma patients. CDH1 rs16958383 represents single-nucleotide polymorphisms associated with airway remodelling (rs7188750, rs8056633, rs16958383, rs2276330, rs3785878, rs7203904 and rs17690554). General linear models were used to estimate the means of each dependent variable adjusted for sex, age and smoking. a) Epithelial E-cadherin expression, expressed as \% basement membrane (BM) covered with E-cadherin-positive intact epithelium. $\bullet$ : subjects; - : median. b) CD31+ vessels per 0.1 mm² submucosal area. c) BM thickness. d) Post-bronchodilation (BD) forced expiratory volume in $1 \mathrm{~s}\left(F E V_{1}\right) /$ vital capacity (VC) ratio. e) Annual change in FEV1. f) CD8+ T-cells per 0.1 mm² submucosal area. g) Eosinophils per $0.1 \mathrm{~mm}^{2}$ submucosal area. - mean; whiskers: $95 \% \mathrm{Cl}$. ICS: inhaled corticosteroid. Bold indicates significance.

no relationship between $\mathrm{BM}$ thickness and lung function tests, such as FEV1, FEV1/VC, residual volume \% predicted and total lung capacity \% predicted, but they included only asthmatic patients who never used ICS or who were withdrawn from ICSs for $\geqslant 3$ months. Our study suggests that discrepant findings may, at least partially, be due to a modulating effect of both ICSs and CDH1 SNPs on airway remodelling and lung function. As previous studies have shown, treatment with ICSs may reduce or control the intensity of airway remodelling, improve FEV1 and reduce loss of lung function [30-32]. It has yet to be elucidated how ICSs prevent these adverse effects. Based on our findings and on evidence that corticosteroids upregulate cadherin expression $[18,33]$, we speculate that ICS interaction with CDH1 SNPs might be one possible explanation.

The fact that we do not observe significant differences in epithelial E-cadherin expression between the mutant and wildtype alleles during ICS use could be attributed to the fact that the mutant alleles interact with ICSs and promote E-cadherin upregulation to a similar level as the wild-types. However, in the absence of ICS the mutant alleles are not capable of producing the same amount of protein compared to wild types. The nearly significant, inverse association we found between damaged/denuded epithelium and epithelial E-cadherin expression indicates that E-cadherin is involved in epithelial integrity, and it is probable that epithelial damage is increased in subjects with lower E-cadherin expression.

In our study, we also observed that specific $C D H 1$ polymorphisms, in the presence of ICSs, tended to be associated with recruitment of CD8+ T-cells in the submucosa. Previously, SONT et al. [34] found that despite ICS treatment, CD8+ T-cell infiltration might persist in asthma patients and that CD8+, but not CD4+, cells are associated with BHR [34] and lung function decline [35], and recently, HiROSAKO et al. [8] showed that CD8 and CD103 (ligand for E-cadherin) are highly expressed in asthmatic bronchial intraepithelial lymphocytes. In that study, the percentage of CD8+ cells was higher than the percentage of CD4+ cells in intraepithelial lymphocytes in asthma. The expression of CD103 was significantly higher in 
CD8+ cells compared with CD4+ cells, suggesting that the interaction between E-cadherin (CD103) and CD8+ cells is the reason for the higher percentage of CD8+ cells in asthmatic intraepithelial lymphocytes [8]. Furthermore, CEPEK et al. [36] demonstrated that T-cells express a member of the cadherin superfamily and this may contribute to T-cell-mediated immune surveillance via heterotypic adhesions with mucosal epithelial cells. Combining these findings, we could speculate that there might be a link between specific $C D H 1$ polymorphisms and expression or binding of E-cadherin on T-cells, a finding that needs further investigation.

One could suggest that the lack of multiple testing correction is responsible for the current results. We decided not to apply a sequential (classical) Bonferroni correction for a number of reasons. First, our choice for the current study was explicitly driven by previous observations suggesting E-cadherin expression is related to epithelial integrity, airway remodelling and disease progression. Secondly, the independent variables in our analyses (e.g. airway remodelling and FEV1 decline) are mutually related, indicating that a rigid statistical procedure, such as Bonferroni correction for multiple testing, would not do justice to their biologically linked nature. Finally, although adjustment for multiple testing will decrease the chance of a type I error, it will also increase the chance of a type II error, so that a true association is not found. This is especially possible in a relatively small study such as ours. Thus, we followed the advice given by PERNEGER [37]: "Simply describing what was done and why, and discussing the possible interpretations of each result, should enable the reader to reach a reasonable conclusion without the help of Bonferroni adjustments".

In our study, the associations between the SNPs and the biopsy parameters in population 1 were confirmed in population 2, where the same risk alleles were associated with FEV1 decline. This is called a loose replication [38]. The observed interaction of CDH1 SNPs with ICS use makes it difficult to find another study that is suitable for replication of our results. First, no other study on adult asthma patients exists with longitudinal data on lung function both with and without ICS use during such a long follow-up period. Secondly, bronchial biopsy studies in asthmatics usually investigate fewer patients than our study, which decreases the power to find associations.

In conclusion, our data show that CDH1 SNPs are associated with epithelial E-cadherin expression and suggest that epithelial adhesion is an important contributor to airway remodelling and lung function in asthma. These effects are modified by the use of ICSs.

\section{SUPPORT STATEMENT}

This study was supported, in part, by a grant from the Netherlands Asthma Foundation (AF 3.2.07.15).

\section{STATEMENT OF INTEREST}

Statements of interest for D.S. Postma and G.H. Koppelman can be found at www.erj.ersjournals.com/site/misc/statements.xhtml

\section{ACKNOWLEDGEMENTS}

We thank F. Volbeda and A. Dijkstra (Dept of Pulmonology, University Medical Center Groningen (UMCG), Groningen, the Netherlands) for collecting the biopsies, M. Broekema and M. Lodewijk (Dept of Pathology and Medical Biology, UMCG) for processing and staining of the biopsies, and M. Olivier (Dept of Genetics, UMCG) for her help with genotyping.

\section{REFERENCES}

1 Montefort S, Djukanović R, Holgate ST, et al. Ciliated cell damage in the bronchial epithelium of asthmatics and non-asthmatics. Clin Exp Allergy 1993; 23: 185-189.

2 Jeffery PK, Wardlaw AJ, Nelson FC, et al. Bronchial biopsies in asthma. An ultrastructural, quantitative study and correlation with hyperreactivity. Am Rev Respir Dis 1989; 140: 1745-1753.

3 Chanez P. Severe asthma is an epithelial disease. Eur Respir J 2005; 25: 945-946.

4 Ricciardolo FL, Di Stefano A, van Krieken JH, et al. Proliferation and inflammation in bronchial epithelium after allergen in atopic asthmatics. Clin Exp Allergy 2003; 33: 905-911.

5 Cavey M, Lecuit T. Molecular bases of cell-cell junctions stability and dynamics. Cold Spring Harb Perspect Biol 2009; 1: a002998.

6 Pokutta S, Weis WI. Structure and mechanism of cadherins and catenins in cell-cell contacts. Annu Rev Cell Dev Biol 2007; 23: 237-261.

7 Aberle H, Schwartz H, Kemler R. Cadherin-catenin complex: protein interactions and their implications for cadherin function. J Cell Biochem 1996; 61: 514-523.

8 Hirosako S, Goto E, Tsumori K, et al. CD8 and CD103 are highly expressed in asthmatic bronchial intraepithelial lymphocytes. Int Arch Allergy Immunol 2010; 153: 157-165.

9 Vonk JM, Jongepier H, Panhuysen CIM, et al. Risk factors associated with the presence of irreversible airflow limitation and reduced transfer coefficient in patients with asthma after 26 years of follow up. Thorax 2003; 58: 322-327.

10 Dijkstra A, Vonk JM, Jongepier H, et al. Lung function decline in asthma: association with inhaled corticosteroids, smoking and sex. Thorax 2006; 61: 105-110.

11 Ward C, Pais M, Bish R, et al. Airway inflammation, basement membrane thickening and bronchial hyperresponsiveness in asthma. Thorax 2002; 57: 309-316.

12 Benayoun L, Letuve S, Druilhe A, et al. Regulation of peroxisome proliferator-activated receptor gamma expression in human asthmatic airways: relationship with proliferation, apoptosis, and airway remodeling. Am J Respir Crit Care Med 2001; 164: 1487-1494.

13 Foty RA, Corbett SA, Schwarzbauer JE, et al. Dexamethasone upregulates cadherin expression and cohesion of HT-1080 human fibrosarcoma cells. Cancer Res 1998; 58: 3586-3589.

14 Broekema M, ten Hacken NHT, Volbeda F, et al. Airway epithelial changes in smokers but not in ex-smokers with asthma. Am J Respir Crit Care Med 2009; 180: 1170-1178.

15 Broekema M, Timens W, Vonk JM, et al. Persisting remodeling and less airway wall eosinophil activation in complete remission of asthma. Am J Respir Crit Care Med 2011; 183: 310-316.

16 Standards for the diagnosis and care of patients with chronic obstructive pulmonary disease (COPD) and asthma. Am Rev Respir Dis 1987; 136: 225-244.

17 Rasmussen F, Taylor DR, Flannery EM, et al. Risk factors for airway remodeling in asthma manifested by a low postbronchodilator FEV1/vital capacity ratio: a longitudinal population study from childhood to adulthood. Am J Respir Crit Care Med 2002; 165: 1480-1488.

18 Carayol N, Campbell A, Vachier I, et al. Modulation of cadherin and catenins expression by tumour necrosis factor- $\alpha$ and dexamethasone in human bronchial epithelial cells. Am J Respir Cell Mol Biol 2002; 26: 341-347.

19 Carayol N, Vachier I, Campbell A, et al. Regulation of E-cadherin expression by dexamethasone and tumour necrosis factor- $\alpha$ in nasal epithelium. Eur Respir J 2002; 20: 1430-1436.

20 Rijcken B, Weiss ST. Longitudinal analyses of airway responsiveness and pulmonary function decline. Am J Respir Crit Care Med 1996; 154: S246-S249. 
21 Foty RA, Corbett SA, Schwarzbauer JE, et al. Dexamethasone upregulates cadherin expression and cohesion of HT-1080 human fibrosarcoma cells. Cancer Res 1998; 58: 3586-3589.

22 Boivin MA, Ye D, Kennedy JC, et al. Mechanism of glucocorticoid regulation of the intestinal tight junction barrier. Am J Physiol Gastrointest Liver Physiol 2007; 292: G590-G598.

23 De Boer WI, Sharma HS, Baelemans SMI, et al. Altered expression of epithelial junctional proteins in atopic asthma: possible role in inflammation. Can J Physiol Pharmacol 2008; 86: 105-112.

24 Muise AM, Walters TD, Glowacka WK, et al. Polymorphisms in Ecadherin (CDH1) result in a mis-localised cytoplasmic protein that is associated with Crohn's disease. Gut 2009; 58: 1121-1127.

25 Bernstein CN, Wajda A, Blanchard JF. The clustering of other chronic inflammatory diseases in inflammatory bowel disease: a population-based study. Gastroenterology 2005; 129: 827-836.

26 Schreiber S, Rosenstiel P, Albrecht M, et al. Genetics of Crohn disease, an archetypal inflammatory barrier disease. Nat Rev Genet 2005; 6: 376-388.

27 UK IBD Genetics Consortium, Barrett JC, Lee JC, et al. Genomewide association study of ulcerative colitis identifies three new susceptibility loci, including the HNF4A region. Nat Genet 2009; 41: 1330-1334

28 Houlston RS, Webb E, Broderick P, et al. Meta-analysis of genomewide association data identifies four new susceptibility loci for colorectal cancer. Nat Genet 2008; 40: 1426-1435.

29 Kosciuch J, Przybylowski T, Gorska K, et al. Relationship between airway basement membrane thickness and lung function tests in patients with asthma. Pneumonol Alergol Pol 2009; 77: 256-263.
30 Olivieri D, Chetta A, Del Donno M, et al. Effect of short-term treatment with low-dose inhaled fluticasone propionate on airway inflammation and remodeling in mild asthma: a placebo-controlled study. Am J Respir Crit Care Med 1997; 155: 1864-1871.

31 Chetta A, Zanini A, Foresi A, et al. Vascular component of airway remodeling in asthma is reduced by high dose of fluticasone. Am J Respir Crit Care Med 2003; 167: 751-757.

32 O'Byrne PM, Pedersen S, Busse WW, et al. Effects of early intervention with inhaled budesonide on lung function in newly diagnosed asthma. Chest 2006; 129: 1478-1485.

33 Blecharz KG, Drenckhahn D, Forster CY. Glucocorticoids increase VE-cadherin expression and cause cytoskeletal rearrangements in murine brain endothelial cEND cells. J Cereb Blood Flow Metab 2008; 28: 1139-1149.

34 Sont JK, Han J, van Krieken JM, et al. Relationship between the inflammatory infiltrate in bronchial biopsy specimens and clinical severity of asthma in patients treated with inhaled steroids. Thorax 1996; 51: 496-502.

35 van Rensen ELJ, Sont JK, Evertse CE, et al. Bronchial CD8 cell infiltrate and lung function decline in asthma. Am J Respir Crit Care Med 2005; 172: 837-841.

36 Cepek KL, Rimm DL, Brenner MB. Expression of a candidate cadherin in T lymphocytes. Proc Natl Acad Sci USA 1996; 93: 6567-6571.

37 Perneger TV. What's wrong with Bonferroni adjustments. $B M J$ 1998; 316: 1236-1238.

38 Holloway JW, Koppelman GH. Identifying novel genes contributing to asthma pathogenesis. Curr Opin Allergy Clin Immunol 2007; 7: 69-74. 